\title{
Critical Thinking in the Teaching of Linguistics
}

\author{
Liu Jianwen \\ School of Foreign Languages, Wuhan Polytechnic University, Wuhan, 430024, China
}

\begin{abstract}
Theories of every discipline are rooted in philosophy and require critical thinking to get them through. Studies in linguistics are no exception. This paper, taking perspectives of segmentation and rationality, presents analysis of one problem-the conflict between the Cooperative Principle and its maxims - the violations of maxims and the observation of the Cooperative Principle, which obsesses many beginners of linguistics; from this discussion, we can find that some linguistic theories (pragmatic theories in particular) develop from and therefore are rooted in philosophy. So, when we deal with some linguistic theories, we should not only observe them for the sake of linguistics superficially, but also find out their philosophical background to help us get a thorough understanding of them; during this process, we should learn to think about, analyze and solve linguistic problems philosophically.
\end{abstract}

Key words: Critical Thinking; the Teaching of Linguistics; Cooperative Principle; Segmentation; Intentionality;

\section{Introduction}

$B e$ is one of the most discussed topics in western philosophy. The philosophical study of it begins with and forms ontology-- "What is being? What is the nature of the world". When there is no desired answers, the study turns to the second phase--epistemology (i.e., How do humans interpret being? What is the relation between thinking and being, and what is the source, capability and limit of human's knowledge?) (Qian Guanlian, 1999: 9). Can philosopher, especially philosophers of language, find the desired answers to them? Are they avoiding those questions or approaching their goal? Philosophers are always optimistic, because they're never afraid of questions--they were born to think about, propose and solve problems. This deserves our respect: their courage and unique perspective in thinking. So the inspiration for us is: as long as we're willing to and dare to think, there is always the way to understand and solve problems. This article aims to clear the following confusion in college students' learning linguistics, which is concerned with Grice's Cooperative Principle--if principle should be followed but at the same time violated, then it contradicts with the law of identity. (Zhao Yanchun, 2005: 76) That confuses many beginners of linguistics--if only the maxims or submaxims are violated while the general principle is abode by, then it is illogical. Of course, that is not what Grice meant by proposing Cooperative Principle.

\section{The 'Conflict' in the Cooperative Principle}

Cooperative Principle ( $\mathrm{CP}$ for short) is one of the fundamental theories of linguistics, pragmatics in particular, which needs no detailed introduction here. As a linguistics teacher, I found that the question confuses most college students is: Grice discusses the violations of maxims after explaining $\mathrm{CP}$. We know that the observance of $\mathrm{CP}$ is the premise of successful conversations. So, how could the maxim(s) (which will result in implicature) be violated at the same time $\mathrm{CP}$ observed? Here is where critical thinking words. I will analyze this phenomenon from the following two perspectives: segmentation and intentionality. 


\section{Segmentation}

In the second phase of generative grammar, (i.e., Standard Theory), Chomsky put forward the hypotheses of 'deep structure' and 'surface structure' to get a deeper understanding of the structures of sentences. This double structure became the core concepts in the period of his theory. In fact, before Chomsky, some philosophers and linguists have expressed similar ideas. Wittgenstein discussed the relation between deep grammar and surface grammar; Hockeet also adopted similar concepts in $A$ Course in Modern Linguistics. All they try to say is that we should differentiate what is expressed directly and what is expressed indirectly. (editorial board of Foreign Languages Research, 1982: 87) Withe the same purpose, Chomsky discussed ambiguity with similar approach in his syntactic analysis (ibd.: 93)

This binary division gives us such a thought: we should segment or reduce questions we face to their most base forms. The following is an example of lexical rhetorical device. E.g.:

The thief made a trembling confess of his wrongdoings.

(Li Xinhua, 2000: 63)

Obviously, this is a transferred epithet. It is the thief not the confess that trembles. This makes sense to us, but why can we get such an understanding? This problem can be solved with the concept of double structure. Now we will rewrite the the sentence (in the form of surface structure) with its two deeper structures:

a. The thief did wrong doings.

b. The thief made a confession.

c. The thief was trembling when he made a confession.

From the analysis above, this transferred epithet violates both Quality maxim and Quantity maxim on the surface level, but it abides by Cooperative Principle on the deep level. This accords with human cognition. We can regard expressions on the surface level as the result of the transformation and combination of the three expressions on the deep structure. The double structures of both rhetorical device and Cooperative Principle can be analyzed respectively and shown in the following table:

Table 1: two levels of structure in the violations of Grciean maxims in stylistic lexical devices:

\begin{tabular}{|c|c|c|}
\hline Two levels of structure & Surface structure & Deep structure \\
\hline Lexical stylistic devices & What is literally said/written & What is implied \\
\hline $\begin{array}{c}\text { Gricean maxims (in lexical } \\
\text { stylistic devices) }\end{array}$ & $\begin{array}{c}\text { One or more Gricean maxims are } \\
\text { violated }\end{array}$ & $\begin{array}{c}\text { The CP is observed at a deep } \\
\text { level }\end{array}$ \\
\hline
\end{tabular}

(Liu Jianwen, 2009: 154)

As we know, many rhetorical devices have both literal meaning and implied meaning. This accords with the violation of one or more Gricean maxims on the surface level and the observance of CP on the deep level. The end of the double structure is implied meaning and conversational implicature, which are same in nature. In the above table, when Gricean maxims are violated, observing the $\mathrm{CP}$ at a deep level, implicature is generated. Note that implicature, as a media, bridges the gap between lexical stylistic devices and Gricean maxims, for implicature itself is a kind of implied meaning (Hu Zhuanglin, 2001). In fact, almost all the examples of lexical rhetorical devices are justified to be analyzed from the perspective of the violations Gricean maxims. So, the critical thinking, segmentation here is vital in understanding and mastering the theory of conversational implicature. 


\section{Intentionality}

After the linguistic turning of philosophy, meaning becomes the centre topic of it. Philosophers see the speakers' intention as the main component of meaning. (Qian, 2005: 65) Rationality and intentionality, accordingly, become the core concepts in Grice's theory of conversational implicature. "intentionality is one of the most important concepts in Grice's theory of meaning, and it decides the meaning of conversations." (Xu Guangwu, 2006: 7) Besides, Grice mentioned "rational" and "rationalist" several times. Those two concepts are very helpful in answering the question we raised at the beginning of this article. Theories of meaning, in its philosophical sense, attach great importance to the elements of humans, such as rationality and intentionality in particular. That's because human activities, including speech acts, are done with specific purposes. Speech acts are carried out to communicate and therefore, they carry the speakers" intention and are "governed" by rationality. Hou (Hou Guojin, 2006: 11) points out that "both Grice's and Searle's theories can be called theories of rationality or intentionality. Whether the two parties of speech acts cooperate or not agrees with their intention." Therefore, we provide the following solution to the problem confusing college students: if the seemingly intro-linguistic (purely concerned with language) non-cooperation expressions transmit the speakers' intention, that is to say, as long as the two parties can communicate with each other successfully, they should be regarded as cooperative. Now it's clear that this type of critical thinking about rationality or intentionality can help the students better understand and master the concerned linguistic theories.

Broadly speaking, as a special form of communication, lexical stylistic devices, either in written or spoken form, help people communicate effectively aided by their aesthetic function via violating Gricean maxims of the CP literally and on purpose. Many examples of the violations of Gricean maxims given, it is not difficult to find that there is a double-structure in both of lexical stylistic devices and Gricean maxims. These two structures can be connected by conversational implicature, whose generation helps realize the aesthetic function of lexical stylistic devices.

\section{III .CONCLUSIONS}

From what we discuss above, it is no difficult to say that if we do not explain some linguistic theories with critical thinking (be it the philosophical background or else), it will be difficult to for our students take in those theories. The reasons are easy: most linguistic theories (pragmatic theories in particular) are rooted in philosophy (especially philosophy of language). This is also an inevitable outcome of the linguistic turn of philosophy, although the philosophers (of language) did not meant to analyze philosophy in this way. It brings us very useful implications about Linguistics teaching: we should encourage the students to think critically, to see through the appearance of some linguistic theories to perceive the essence of them; what's more, students should learn to think and analyze questions to finally solve them. Therefore, in teaching linguistics, what is more important than linguistic theories is the critical thinking beneath them. Only in this way can we help them to know what is the main content of a specific theory as well as why it is so. 


\section{References:}

[1] Grice, H. P. Logic and conversation. In Cole, P. \& J. Morgan (eds.) Syntax and Semantics 3: Speech Acts[C]. New York: Academic Press, 1975: 41-58.

[2] Feng Guangwu. Rationality in Grice' s Theory of Meaning[J]. Foreign Languages Research, 2006 (4): 6-11.

[3] Editorial Board of Foreign Language Research. Introduction to Chomsky's theory of meaning[C]. 1982.

[4] Hou Huojin. Pragmatic Markedness Relevance-Model--a perspective of classic and neo-Gricean pragmatics[J]. Foreign Languages Education, 2006 (3): 8-14.

[5] $\mathrm{Hu}$ Zhuanglin. Introduction to Linguistics $\left(4^{\text {th }}\right.$ Ed.)[M]. Beijin: Peking University Press. 2011.

[6] Li Xinhua. Detailed Analysis of English Rhetorical Devices[M]. Shanghai: Shanghai Foreign Language Education Press, 2000.

[7] Liu, Jianwen. The Violations of Grciean Maxims in Stylistic Lexical Devices[J]. Jounal of Chongqing Institute of Arts and Sciences (social science edition), 2009 (6): 152-154.

[8] Qiang, Guanlian. Languages researches in orbit around philosophy of west[J]. Foreign Languages, 1999 (6): 9-16.

[9] Qiang, Guanlian. Philosophical background of Pragmatics[J]. Foreign Languages and Their Teaching, 1999 (6): 4-8.

[10] Qiang, Guanlian. Language: The Last Homestead of Human Beings[M]. Beijing: Commercial Press. 2005.

[11] Searle, John. Mind, Language and Society[M], (translated by Li Bulou). Shanghai: Shanghai Translation Publishing House. 2006.

[12] Zhao, Yanchun. The Philosophical Criticism of Linguistics[M]. Chongqing: Chongqing Publishing House. 2005. 